\title{
Synergistic Effect of Eicosapentaenoic Acid on Antiproliferative Action of Anticancer Drugs in a Cancer Cell Line Model
}

\author{
Ayako Ogo $^{a}$ Sachi Miyake ${ }^{a}$ Hisako Kubota ${ }^{b}$ Masaharu Higashida ${ }^{b}$ \\ Hideo Matsumoto $^{c}$ Fusako Teramoto $^{a}$ Toshihiro Hirai $^{a}$ \\ ${ }^{a}$ Department of Clinical Nutrition, Faculty of Health Science and Technology, Kawasaki University of Medical \\ Science, Kurashiki, Japan; ${ }^{b}$ Department of Digestive Surgery, Kawasaki Medical School, Kurashiki, Japan; \\ 'Mitsugi General Hospital, Onomichi, Japan
}

\section{Keywords}

Eicosapentaenoic acid · Anticancer drug · Synergy

\begin{abstract}
Background/Aims: It has been found experimentally and clinically that eicosapentaenoic acid (EPA) exerts an anticancer effect and that it has a minimal adverse event profile relative to other anticancer drugs. Any synergy between EPA and other anticancer drugs could be of therapeutic relevance, especially in elderly or high-risk patients. Therefore, we investigated the synergism between anticancer drugs and EPA experimentally. Methods: EPA was coadministered in vitro with various anticancer drugs (paclitaxel, docetaxel, 5-fluorouracil and cis-diamminedichloridoplatinum[II]) to TE-1 cells, which were derived from human esophageal cancer tumors. Cell proliferation was measured by the water soluble tetrazolium-1 method. Result: Sub-threshold concentrations of EPA, which alone produced no anticancer effect, caused a synergistic suppressive effect on TE-1 cell proliferation when combined with other anticancer agents. Conclusion: Coadministration of EPA with other anticancer drugs may represent a new therapeutic paradigm offering a reduced side effect profile.

(c) 2017 S. Karger AG, Basel
\end{abstract}

\section{KARGER}

(c) 2017 S. Karger AG, Basel

E-Mail karger@karger.com

www.karger.com/anm

\section{Introduction}

Although the prognosis for esophageal cancer patients receiving operative treatment has shown improvement in recent years, it is still very poor when the disease is in an advanced stage and/or is recurrent. Several drugs, such as paclitaxel, ocetaxel, 5-fluorouracil (5-FU), and cisdiamminedichloridoplatinum(II) (CDDP or cisplatin) [1-7], have been found to be efficient against esophageal cancer. Paclitaxel and docetaxel bind to microtubules, disturbing their normal separation at cell division, thereby reducing tumor progression. The anti-tumor effect of 5-FU (a nucleotide) is by the disruption of DNA structure, while CDDP is an alkylating agent that cross-links DNA strands and precludes their separation into single strands at cell division. In esophageal cancer treatment, combination therapy with CDDP and 5-FU is the current gold standard [8] and has significant reported efficacy [9].

Eicosapentaenoic acid (EPA) is a polyunsaturated omega-3 fatty acid. It is abundant in fish oil and is known to reduce platelet aggregation [10]. EPA has been reported to improve lipid metabolism [11, 12], and is useful in the treatment of atherosclerosis [13], coagulation defects [10] and glucose metabolism abnormalities [14]. Furthermore, it exhibits antiprolifera- 
tive activity in cells derived from various cancer types, notably in the types that affect the pancreas and breasts [15-17].

We reported previously that EPA suppresses the activity of nuclear factor-kappa B (NF- $\kappa B$; which is implicated in acute and chronic inflammation, cell proliferation, cell transcription, and many other physiological phenomena including apoptosis) and that it produces apoptosis in TE-1 esophageal cancer cells [18]. The halfmaximal inhibitory concentration (IC50) of EPA was determined to be $260 \mu \mathrm{M}$ [18], and concentrations below $\sim 200 \mu \mathrm{M}$ showed no anticancer activity. EPA also inhibits lipopolysaccharide-induced interleukin- 6 production by cancer cells [18], and has very few adverse effects [10] - an attractive property for an anticancer treatment in an aging society that is susceptible to the negative effects of therapeutic regimes. An ideal therapy would have the efficacy of a traditional anticancer drug together with the minimal side-effect profile of EPA. We therefore investigated whether EPA has a synergistic effect on the activity of these anticancer agents that might allow them to be used at lower doses and with fewer side effects.

\section{Materials and Methods}

\section{Cell Lines}

We used the TE- 1 cell line, which originates from a human esophageal cancer and was purchased from the Institute of Physical and Chemical Research (Wako, Japan). Cells were cultured at $37^{\circ} \mathrm{C} / 5 \% \mathrm{CO}_{2}$ in RPMI-1640 medium supplemented with $10 \%$ FBS, penicillin $(100 \mathrm{U} / \mathrm{mL})$, and streptomycin $(100 \mu \mathrm{g} / \mathrm{mL}$; all from Sigma-Aldrich Co., Ltd., St. Louis, MO, USA). Cis-5, 8, 11, 14, 17-EPA (sodium salt) was also purchased from Sigma-Aldrich and dissolved in PBS before use. EPA was coadministered with one of 4 anticancer drugs: paclitaxel (Nippon Kayaku Co., Ltd., Tokyo, Japan), docetaxel (Towa Pharmaceutical Co., Ltd., Osaka, Japan), 5-FU (Kyowa Hakko Kirin Co., Ltd., Tokyo, Japan), and CDDP (Nichi-Iko Pharmaceutical Co., Ltd., Toyama, Japan).

Water Soluble Tetrazolium-1 Cell Proliferation Assay

TE- 1 cells $\left(2 \times 10^{3}\right.$ cells/well $)$ were seeded into 96 well plates and grown for $24 \mathrm{~h}$ after which the medium was refreshed and supplemented with EPA and either paclitaxel, docetaxel, 5-FU, or CDDP. At 24, 48, or $72 \mathrm{~h}$ after drug administration, culture medium was changed and $10 \mu \mathrm{L}$ of water soluble tetrazolium-1 (Takara Co., Ltd., Tokyo, Japan) was added. Cells were then cultured for a further $4 \mathrm{~h}$ at $37^{\circ} \mathrm{C}$ before measurement of absorbance at 450 and $550 \mathrm{~nm}$ wavelengths using a microplate reader (Varioskan Flash; Thermo Fischer Scientific Co., Ltd., MA, USA). The measurement was performed for each data point 8 points in 3 independent experiments.
Statistical Analysis

Statistical significance of differences between groups was evaluated by $t$ test using JMP version 12 software (SAS Institute, Cary, NC, USA). $p$ values in this study were 2 -sided, with $p<0.05$ considered significant.

\section{Results}

\section{EPA and Paclitaxel}

Cell proliferation was suppressed more by the coadministration of EPA and paclitaxel than by paclitaxel alone (Fig. 1a, b). These differences were statistically significant at 10,20 , and $30 \mu \mathrm{g} / \mathrm{mL}$ paclitaxel, and were more pronounced when using $200 \mu \mathrm{M}$ EPA than with $100 \mu \mathrm{M}$ EPA. Results were qualitatively similar after 24 and $48 \mathrm{~h}$ of culture, except that the effect of EPA on the action of $30 \mu \mathrm{g} / \mathrm{mL}$ paclitaxel was not apparent at $48 \mathrm{~h}$ culture.

\section{EPA and Docetaxel}

EPA at $200 \mu \mathrm{M}$ significantly enhanced the suppression of proliferation by $10 \mu \mathrm{g} / \mathrm{mL}$ docetaxel. Furthermore, EPA at both 100 and $200 \mu \mathrm{g} / \mathrm{mL}$ exhibited a significant synergistic effect on 20 and $30 \mu \mathrm{g} / \mathrm{mL}$ docetaxel. This synergy was more pronounced with $200 \mu \mathrm{M}$ EPA than with $100 \mu \mathrm{M}$ EPA. Results were qualitatively similar at 24 and $48 \mathrm{~h}$ of culture (Fig. 2a, b).

\section{EPA and 5-FU}

In contrast, the effects of EPA on the efficacy of 5-FU were small. Indeed, there was no synergy between EPA and 5-FU at any concentration after $24 \mathrm{~h}$ of culture (Fig. 3a). There were small but significant differences at $48 \mathrm{~h}$ (Fig. 3b) and $72 \mathrm{~h}$ (Fig. 3c) between the effects of 5 -FU alone and those in the presence of EPA. Notably, these differences at $72 \mathrm{~h}$ were apparent only for $100 \mu \mathrm{M}$ EPA and were absent with $200 \mu \mathrm{M}$ EPA (Fig. 3c). The synergistic effect between EPA and 5-FU was the smallest among the 4 anticancer drugs.

\section{EPA and CDDP}

At $24 \mathrm{~h}$, there was only a marginal effect of EPA on the antiproliferative effects of CDDP, although this was most noticeable at $10 \mu \mathrm{g} / \mathrm{mL}$ CDDP (Fig. 4a). The synergistic effects of EPA were more marked at $48 \mathrm{~h}$ (Fig. $4 \mathrm{~b}$ ) and $72 \mathrm{~h}$ (Fig. 4c). Indeed, the enhancement in the antiproliferative activity of CDDP by EPA was apparently EPA-dose-dependent at $48 \mathrm{~h}$, being greater with $200 \mu \mathrm{M}$ EPA than with $100 \mu \mathrm{M}$ EPA. The synergy was particularly profound at $48 \mathrm{~h}$ for $200 \mu \mathrm{M}$ EPA coadministered with $10 \mu \mathrm{g} / \mathrm{mL}$ CDDP 


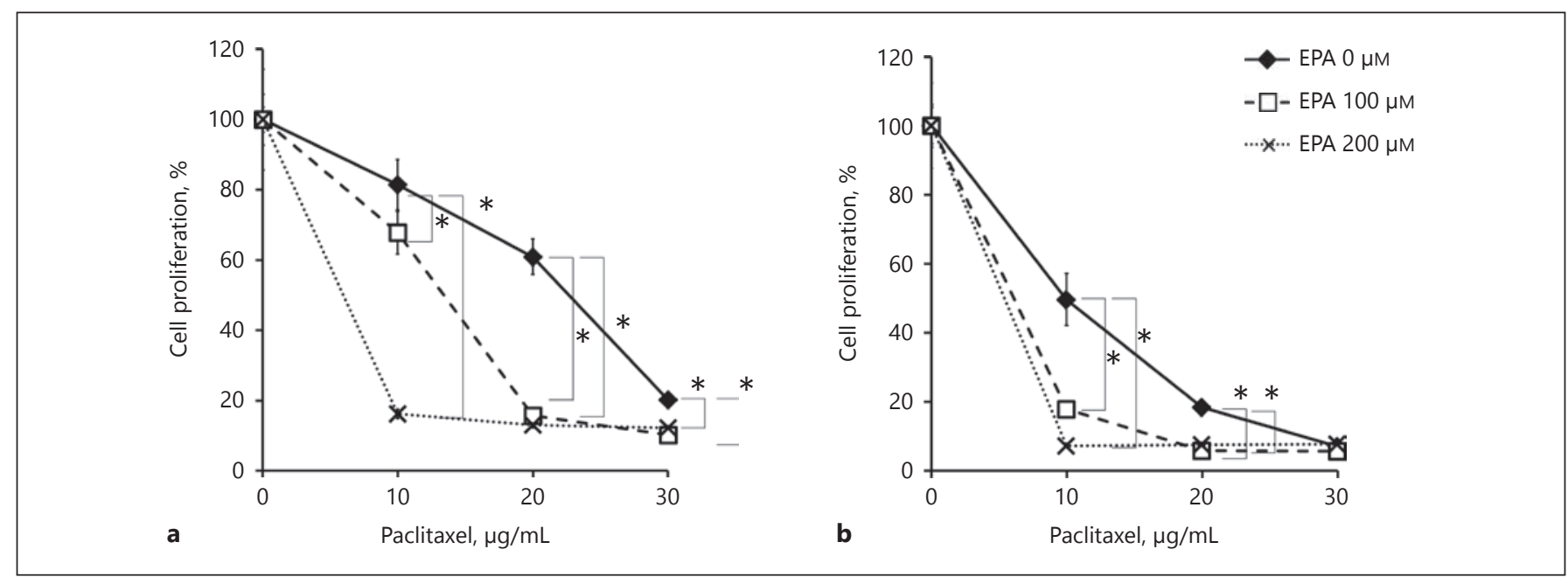

Fig. 1. Proliferation rate for TE- 1 cells cultured with EPA and paclitaxel at the indicated doses for $24 \mathrm{~h}$ (a) and $48 \mathrm{~h} \mathrm{(b).} \mathrm{Cell} \mathrm{proliferation} \mathrm{was} \mathrm{measured} \mathrm{using} \mathrm{the} \mathrm{water} \mathrm{soluble} \mathrm{tetrazolium-1} \mathrm{colorimetric} \mathrm{assay.}{ }^{*}$ Denotes a statistically significant difference $(p<0.01)$ between indicated data points, as assessed by $t$ test.

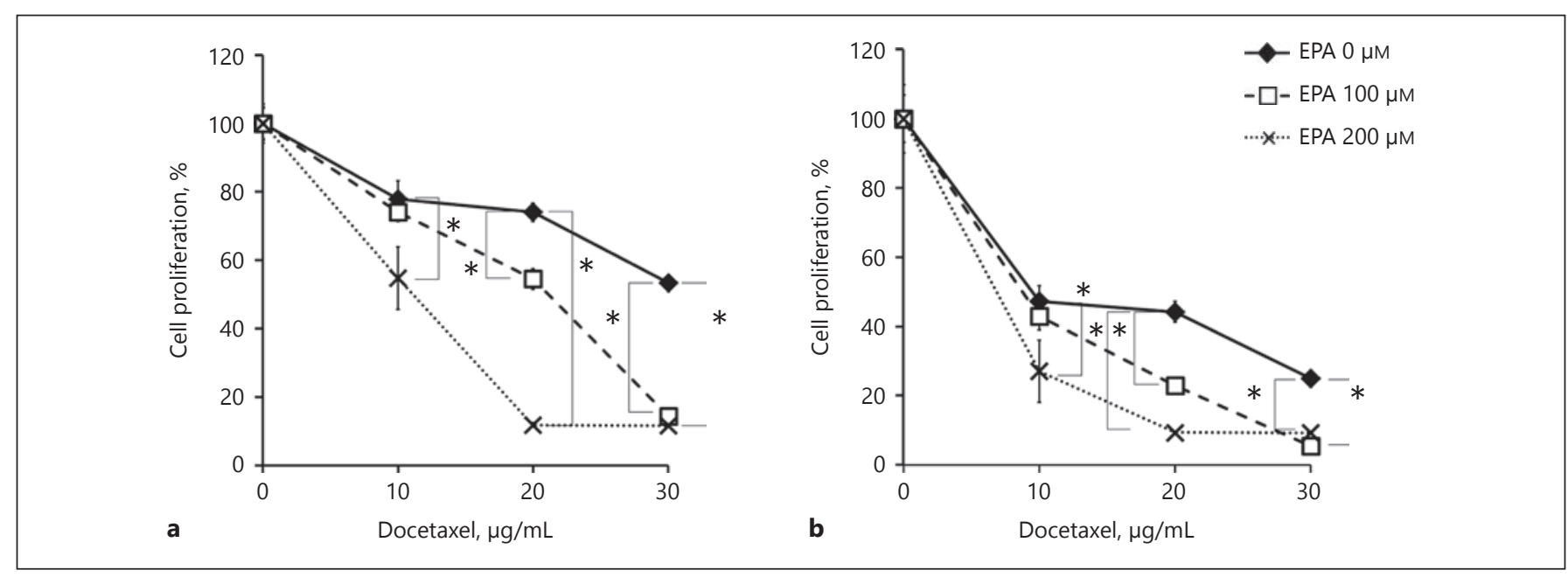

Fig. 2. Proliferation rate for TE-1 cells cultured with EPA and docetaxel at the indicated doses for $24 \mathrm{~h}$ (a) and $48 \mathrm{~h}$ (b). Cell proliferation was measured using the water soluble tetrazolium-1 colorimetric assay. ${ }^{*}$ Denotes a statistically significant difference $(p<0.01)$ between indicated data points, as assessed by $t$ test.

and, to a lesser extent, $5 \mu \mathrm{g} / \mathrm{mL}$ CDDP. Overall, the antiproliferative synergy between EPA and CDDP was smaller than for paclitaxel and docetaxel, but larger than for 5-FU.

\section{Discussion}

Patients with advanced and recurrent esophageal cancer continue to have disappointingly poor prognosis, despite improved treatment outcomes for patients receiving chemoradiotherapy [19]. Esophageal cancer prevalence is highest in patients aged above 60 years. Statistical data from 2011 in Japan revealed a prevalence of $69.8 \%$ for esophageal cancer in this age group. Whereas the highest age of onset in 1991 was 60-64 years, it had increased to $70-74$ years by 2011 [20]. Furthermore, the percentage of the population aged 65 or over was $26.0 \%$ in 2014, and is predicted to rise to $39.9 \%$ in 2016 [21]. It is therefore clear that we are treating a disease that increases in prevalence in elderly patients, and that this patient subgroup repre- 


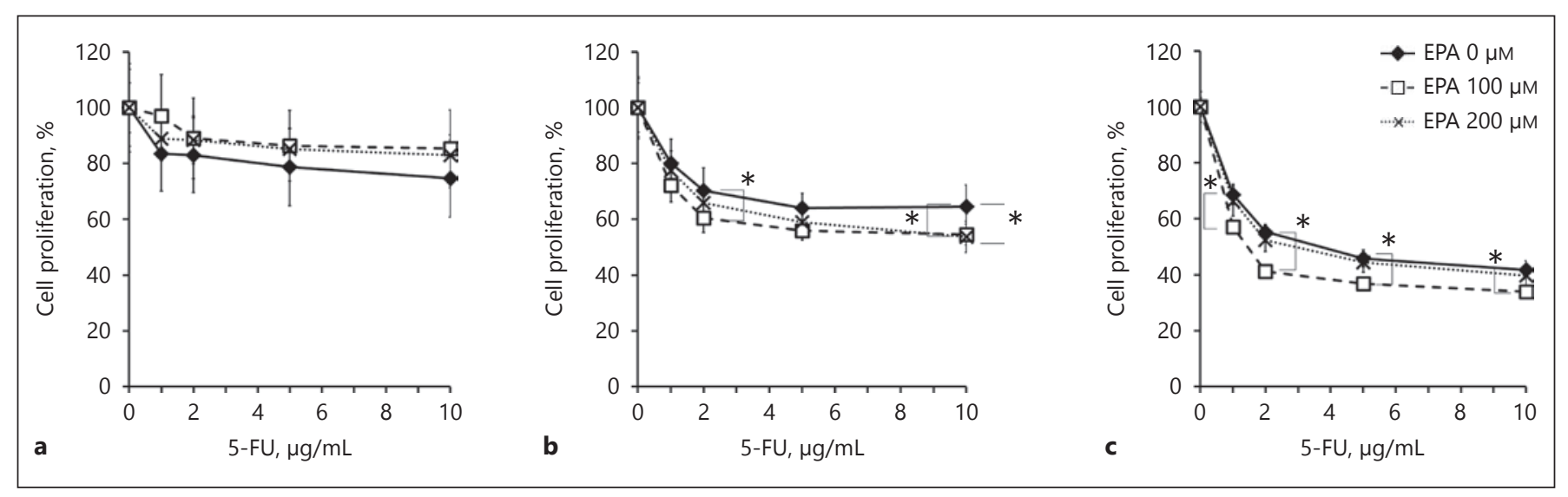

Fig. 3. Proliferation rate for TE-1 cells cultured with EPA and 5-FU at the indicated doses for $24 \mathrm{~h}(\mathbf{a}), 48 \mathrm{~h}$ (b) and $72 \mathrm{~h}(\mathbf{c})$. Cell proliferation was measured using the water soluble tetrazolium-1 colorimetric assay. ${ }^{*}$ Denotes a statistically significant difference $(p<0.01)$ between indicated data points, as assessed by $t$ test.

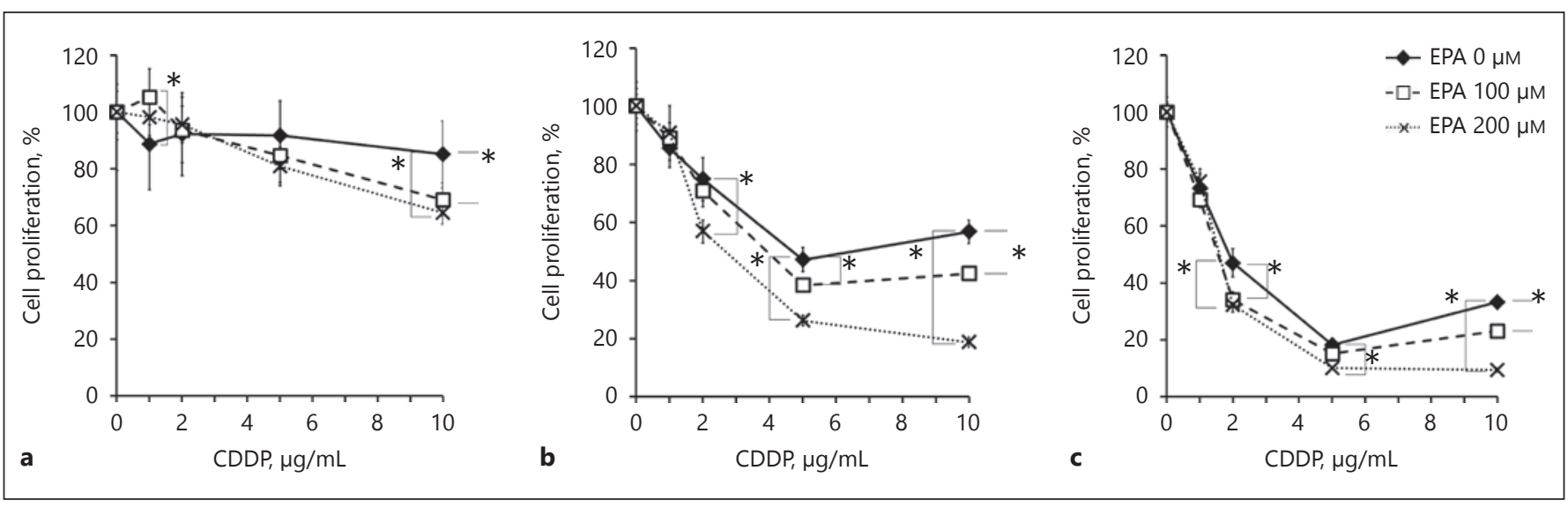

Fig. 4. Proliferation rate for TE-1 cells cultured with EPA and CDDP at the indicated doses for $24 \mathrm{~h}$ (a), $48 \mathrm{~h}$ (b) and $72 \mathrm{~h}(\mathbf{c})$. Cell proliferation was measured using the water soluble tetrazolium-1 colorimetric assay. ${ }^{*}$ Denotes a statistically significant difference $(p<0.01)$ between indicated data points, as assessed by $t$ test.

sents an increasingly large proportion of the population. Elderly patients often present with various lifestyle-related diseases (e.g., high blood pressure, diabetes, hyperlipidemia) and other serious comorbidities that may preclude surgical intervention in many cases. For these complicated cases, a less invasive pharmaceutical therapy with minimal side effects would be desirable.

EPA-an omega-3 polyunsaturated fatty acid (PUFA) has varied bioactivities and produces minimal adverse effects. We reported that EPA suppressed the activity of NF- $\kappa \mathrm{B}$ and caused apoptosis in TE-1 esophageal cancer cells [18]. As for the mechanism of the anticancer effect of PUFAs, especially for gastrointestinal tumor, the apoptosis induction was reported same as our report. In other reports, the apoptosis was revealed to be caused by the activation of caspase $-3,-7,-9$ and poly (ADP-ribose) polymerase proteins [22], the increase of the nuclear receptors constitutive androstane receptor and pregnane $\mathrm{X}$ receptor [23], and the downregulation of FADD-like interleukinlbeta-converting enzyme-inhibitory protein and X-linked inhibitor of apoptosis protein [24]. That means the various cascades could be caused to reach the apoptosis by PUFAs.

Of course, the combination therapy with anticancer drug and PUFAs is required aiming the more strong but safe anticancer effect. A review article summarized that PUFAs, docosahexaenoic acid (DHA), and EPA have the potential to differentially sensitize tissues to chemotherapy, and these lipids enhance the cytotoxicity of 15 anti- 
cancer drugs (antimetabolites, alkylating or intercalating agents, microtubule stabilizers(taxans), Abl tyrosine kinase inhibitor, and arsenic trioxide) to a variety of cancer cell lines or tumors in animals, used as models for breast, prostate, colonic, lung, cervical, ovarian cancers, neuroblastomas, leukemia, or lymphomas; furthermore, 2 phase II clinical trials already support these results [25].

However, there are few reports regarding the combination effect of PUFAs and anticancer drugs for the gastrointestinal cells. We, therefore, used the TE-1 cancer cell line to investigate the interaction between EPA and 4 commonly used anticancer agents (paclitaxel, docetaxel, 5 -FU, CDDP). We reported previously that EPA suppressed the activity of NF- $\kappa$ B with an IC50 of $260 \mu \mathrm{M}$ and also reduced minimal activity at concentrations below $200 \mu \mathrm{M}$ [18]. We thus chose to use subthreshold doses of EPA (100 and $200 \mu \mathrm{M})$ to investigate the synergistic suppressive effect of EPA on the antiproliferative activity of these anticancer drugs. These data suggest that EPA may synergize with existing anticancer drugs to produce greater antiproliferative effects with fewer side effects. Sheng et al. [26] investigated the ability of omega-3 PUFAs to potentiate the anti-neoplastic activity of cisplatin (CDDP) in gastric cancer cells. The enhancement in CDDP-induced growth inhibition was measured as changes in the IC50 values for CDDP alone and in combination with either DHA or EPA. Both DHA and EPA enhanced the growth inhibitory effects of CDDP. The interactions between CDDP and DHA/EPA at the cellular level in MKN45 cells were assessed using the combination index method of Chou-Talalay and were shown to be synergistic. Cell cycle analysis showed that this combination treatment increased G0/G1 phase and S phase arrest, and also significantly increased the number of apoptotic cells. The mechanism was shown to be the higher adenosine A1 receptor mRNA and protein on activating the adenosine A1 receptor-mediated apoptosis pathway in the combination treatment than in the individual treatment.

Regarding the mechanism of the synergism between anticancer drugs and PUFAs, there are more number of reports that highlight the use of DHA than those that explained the use of EPA. Gao et al. [27] reported the significant downregulation of the expression of mitochondrial electron transfer change complexes. Siddiqui et al. [28] reported an important role of cyclooxygenase-2, $\mathrm{NF}-\kappa \mathrm{B}$, peroxisome proliferator-activated receptor gamma, mitogen-activated protein kinese. AKT, and BCL-2/ BAX in DHA-mediated additive or synergistic interaction with anticancer drugs. Zhuo et al. [29] reported the increase of the BAX mRNA.

Synergy between EPA and Anticancer Drugs
We found that coadministration of EPA had variable effects on the efficacy of the anticancer agents, having little effect on the activity of 5-FU but dose-dependently and synergistically suppressing cell proliferation when in combination with docetaxel, paclitaxel, and CDDP. We did not investigate the mechanism of the synergistic effect in this experiment. However, in our previous report, we showed that EPA suppresses NF- $\kappa \mathrm{B}$ activation, which causes apoptosis by increasing the G0/G1 phase and $S$ phase arrest. It remains unclear why subthreshold doses of EPA can act to enhance the actions of various anticancer agents. We could not reveal the mechanism of the synergism between anticancer drugs and PUFAs in these experiments, but many cascades may exist. This thesis should be resolved in the future.

Using immunoreactivity techniques, Takagi et al. [30] showed that after surgical intervention and 3 weeks of chemoradiotherapy-phytohemagglutinin-and concanavalin-A-stimulated lymphocyte proliferation was significantly greater in an EPA-treated group than in a control group. Similarly, natural-killer cell activity was higher in the EPA-treated group than in the control group. This is an indication that mechanisms other than apoptosis might be investigated.

Clinically, EPA and/or DHA from fish oil are administered by capsule or nutritional supplement to increase the percentage of omega-3 fatty acids in the plasma. These PUFAs are effectively incorporated into the cell membrane phospholipids of blood cells [31]. We believe that our findings indicate a putative clinical application of omega-3 PUFAs in optimizing chemotherapy for cancer patients. The next stage of this validation will be to show in an in vivo study and prospective clinical study the effect of combination therapy with PUFAs and anticancer agents.

\section{Conclusion}

The combined administration of EPA and paclitaxel, docetaxel, or CDDP (but not 5-FU) produced a synergistic enhancement of the antiproliferative effect of these anticancer agents in TE-1 cells. These results suggest that coadministration of PUFAs together with certain anticancer drugs may have clinical efficacy and improved side effect profiles, and should be investigated in vivo and clinically.

\section{Author Contribution}

Experimental and statistical analyses were done by A.O. Experimental design was conceived by T.H.

Ann Nutr Metab 2017;71:247-252

251 


\section{References}

-1 Ezdinli EZ, Gelber R, Desai DV, Falkson G, Moertel CG, Hahn RG: Chemotherapy of advanced esophageal carcinoma: Eastern Cooperative Oncology Group experience. Cancer 1980;46:2149-2153.

2 Lokich JJ, Shea M, Chaffey J: Sequential infusional 5-fluorouracil followed by concomitant radiation for tumors of the esophagus and gastroesophageal junction. Cancer 1987; 60:275-279.

-3 Murthy SK, Prabhakaran PS, Chandrashekar M, Deshpande R, Doval DC, Gopinath KS: Neoadjuvant Cis-DDP in esophageal cancers: an experience at a regional cancer centre, India. J Surg Oncol 1990;45:173-176.

-4 Bleiberg H, Conroy T, Paillot B, Lacave AJ, Blijham G, Jacob JH, Bedenne L, Namer M, De Besi P, Gay F, Collette L, Sahmoud T: Randomised phase II study of cisplatin and 5-fluorouracil (5-FU) versus cisplatin alone in advanced squamous cell oesophageal cancer. Eur J Cancer 1997;33:1216-1220.

5 Ajani JA, Ilson DH, Daugherty K, Pazdur R, Lynch PM, Kelsen DP: Activity of taxol in patients with squamous cell carcinoma and adenocarcinoma of the esophagus. J Natl Cancer Inst 1994;86:1086-1091.

-6 Muro K, Hamaguchi T, Ohtsu A, Boku N, Chin K, Hyodo I, Fujita H, Takiyama W, Ohtsu T: A Phase II study of single-agent docetaxel in patients with metastatic esophageal cancer. Ann Oncol 2004;15:955-959.

7 Kato K, Tahara M, Hironaka S, Muro K, Takiuchi H, Hamamoto Y, Imamoto H, Amano N, Seriu T: A Phase II study of paclitaxel by weekly 1 -h infusion for advanced or recurrent esophageal cancer in patients who had previously received platinum-based chemotherapy. Cancer Chemother Pharmacol 2011;67: 1265-1272.

8 Kataoka K, Tsushima T, Mizusawa J, Hironaka S, Tsubosa Y, Kii T, Shibuya Y, Chin K, Katayama H, Kato K, Fukuda H, Kitagawa Y; Japan Esophageal Oncology Group/Japan Clinical Oncology Group: A randomized controlled Phase III trial comparing 2-weekly docetaxel combined with cisplatin plus fluorouracil (2-weekly DCF) with cisplatin plus fluorouracil $(\mathrm{CF})$ in patients with metastatic or recurrent esophageal cancer: rationale, design and methods of Japan Clinical Oncology Group study JCOG1314 (MIRACLE study). Jpn J Clin Oncol 2015;45:494-498.

-9 Scanlon KJ, Newman EM, Lu Y, Priest DG: Biochemical basis for cisplatin and 5-fluorouracil synergism in human ovarian carcinoma cells. Proc Natl Acad Sci U S A 1986;83: 8923-8925.

10 Wiktorowska-Owczarek A, Berezińska M, Nowak JZ: PUFAs: structures, metabolism and functions. Adv Clin Exp Med 2015;24: 931-941.
11 Tanaka K, Ishikawa Y, Yokoyama M, Origasa H, Matsuzaki M, Saito Y, Matsuzawa Y, Sasaki J, Oikawa S, Hishida H, Itakura H, Kita T, Kitabatake A, Nakaya N, Sakata T, Shimada $\mathrm{K}$, Shirato K; JELIS Investigators, Japan: Reduction in the recurrence of stroke by eicosapentaenoic acid for hypercholesterolemic patients: subanalysis of the JELIS trial. Stroke 2008;39:2052-2058.

12 Koba S, Sasaki J: Treatment of hyperlipidemia from Japanese evidence. J Atheroscler Thromb 2006;13:267-280.

13 Borow KM, Nelson JR, Mason RP: Biologic plausibility, cellular effects, and molecular mechanisms of eicosapentaenoic acid (EPA) in atherosclerosis. Atherosclerosis 2015;242: 357-366.

14 Oikawa S, Yokoyama M, Origasa H, Matsuzaki M, Matsuzawa Y, Saito Y, Ishikawa Y, Sasaki J, Hishida H, Itakura H, Kita T, Kitabatake A, Nakaya N, Sakata T, Shimada K, Shirato K; JELIS Investigators, Japan: Suppressive effect of EPA on the incidence of coronary events in hypercholesterolemia with impaired glucose metabolism: Subanalysis of the Japan EPA Lipid Intervention Study (JELIS). Atherosclerosis 2009;206: 535-539.

15 Fukui M, Kang KS, Okada K, Zhu BT: EPA, an omega-3 fatty acid, induces apoptosis in human pancreatic cancer cells: role of ROS accumulation, caspase- 8 activation, and autophagy induction. J Cell Biochem 2013;114: 192-203.

16 Kang KS, Wang P, Yamabe N, Fukui M, Jay T, Zhu BT: Docosahexaenoic acid induces apoptosis in MCF-7 cells in vitro and in vivo via reactive oxygen species formation and caspase 8 activation. PLoS One 2010;5:e10296.

17 D'Eliseo D, Velotti F: Omega-3 fatty acids and cancer cell cytotoxicity: implications for multi-targeted cancer therapy. J Clin Med 2016;5:pii:E15.

18 Kubota $\mathrm{H}$, Matsumoto $\mathrm{H}$, Higashida $\mathrm{M}, \mathrm{Mu}-$ rakami $\mathrm{H}$, Nakashima $\mathrm{H}$, Oka Y, Okumura $\mathrm{H}$, Yamamura M, Nakamura M, Hirai T: Eicosapentaenoic acid modifies cytokine activity and inhibits cell proliferation in an oesophageal cancer cell line. Anticancer Res 2013;33: 4319-4324.

19 Takeuchi H, Kitagawa Y: [Management of esophageal cancer: state of the art]. Nihon Shokakibyo Gakkai Zasshi 2009; 106:753763.

20 Matsuda A, Matsuda T, Shibata A, Katanoda K, Sobue T, Nishimoto H; Japan Cancer Surveillance Research Group: Cancer incidence and incidence rates in Japan in 2008: a study of 25 population-based cancer registries for the monitoring of cancer incidence in Japan (MCIJ) project. Jpn J Clin Oncol 2014;44: 388-396.
21 Cabinet Office: Government of Japan. Annual Report on the Aging Society, 2015. http:// www8.cao.go.jp/kourei/whitepaper/w-2015/ html/gaiyou/s1_1.html (accessed 17.5.8).

22 Mizoguchi K, Ishiguro H, Kimura M, Takahashi H, Sakamoto N, Tanaka T, Takeyama $\mathrm{H}$ : Induction of apoptosis by eicosapentaenoic acid in esophageal squamous cell carcinoma. Anticancer Res 2014;34:7145-7149.

23 Kuan CY, Walker TH, Luo PG, Chen CF: Long-chain polyunsaturated fatty acids promote paclitaxel cytotoxicity via inhibition of the MDR1 gene in the human colon cancer Caco-2 cell line. J Am Coll Nutr 2011;30:265273.

24 Giros A, Grzybowski M, Sohn VR, Pons E, Fernandez-Morales J, Xicola RM, Sethi P, Grzybowski J, Goel A, Boland CR, Gassull MA, Llor X: Regulation of colorectal cancer cell apoptosis by the $n-3$ polyunsaturated fatty acids Docosahexaenoic and Eicosapentaenoic. Cancer Prev Res (Phila) 2009;2:732-742.

25 Hajjaji N, Bougnoux P: Selective sensitization of tumors to chemotherapy by marine-derived lipids: a review. Cancer treat Rev 2013; 39:473-488.

26 Sheng H, Chen X, Liu B, Li P, Cao W: Omega-3 polyunsaturated fatty acids enhance cisplatin efficacy in gastric cancer cells by inducing apoptosis via ADORA1. Anticancer Agents Med Chem 2016;16:1085-1092.

27 Gao K, Kiang Q, Zhao ZH, Li YF, Wang SF: Synergistic anticancer properties of docosahexaenoic acid and 5-fluorouracil through interference with energy metabolism and cell cycle arrest in human gastric cancer cell line AGS cells. World J Gastroenterol 2016;22: 2971-2980

28 Siddiqui RA, Harvey KA, Xu Z, Bammerlin EM, Walker C, Altenburg JD: Docosahexaenoic acid: a natural powerful adjuvant that improves efficacy for anticancer treatment with no adverse effects. Biofactors 2011;37: 399-412.

29 Zhuo Z, Zhang L, Mu Q, Lou Y, Gong Z, Shi Y, Ouyang G, Zhang Y: The effect of combination treatment with docosahexaenoic acid and 5-fluorouracil on the mRNA expression of apoptosis-related genes, including the novel gene BCL2L12, in gastric cancer cells. In Vitro Cell Dev Biol Anim 2009;45:69-74.

30 Takagi K, Yamamori H, Furukawa K, Miyazaki M, Tashiro T: Perioperative supplementation of EPA reduces immunosuppression induced by postoperative chemoradiation therapy in patients with esophageal cancer. Nutrition 2001;17:478-479.

- 31 de Aguiar Pastore Silva J, Emilia de Souza Fabre M, Waitzberg DL: Omega-3 supplements for patients in chemotherapy and/or radiotherapy: a systematic review. Clin Nutr 2015;34:359-366. 